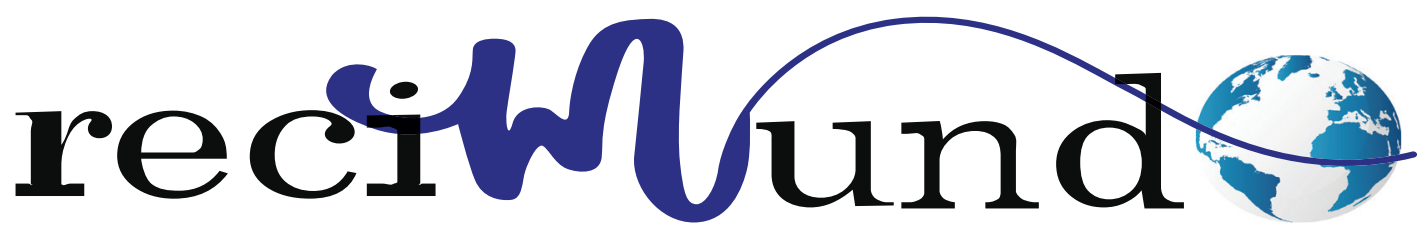

Revista Científica Mundo de la Investigación y el Conocimiento

DOI: 10.26820/recimundo/5.(4).oct.2021.121-131

URL: https://recimundo.com/index.php/es/article/view/1305

EDITORIAL: Saberes del Conocimiento

REVISTA: RECIMUNDO

ISSN: 2588-073X

TIPO DE INVESTIGACIÓN: Artículo de revisión

CÓDIGO UNESCO: 32 Ciencias Médicas

PAGINAS: $121-131$

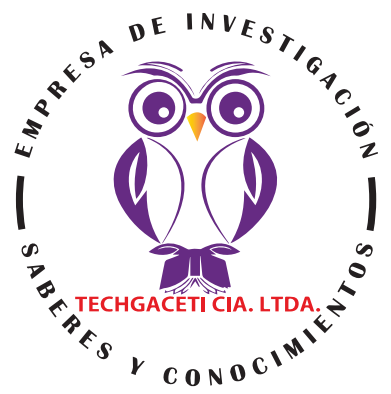

\title{
Abdomen agudo en adolescentes con COVID-19
}

Acute abdomen in adolescents with COVID-19

Abdome agudo em adolescentes com COVID-19

Dennisse Isabel Parreño Grijalva; Henry Alejandro Llaguno Mora²; María Laura Barberán Torres3; Romina Ivanna Mendoza Granda ${ }^{4}$

RECIBIDO: 02/09/2021 ACEPTADO: 20/09/2021 PUBLICADO: 30/10/2021

1. Médica de la Universidad Católica de Santiago de Guayaquil; Investigador Independiente; Guayaquil, Ecuador; dennisse-parreno@gmail.com; (iD https://orcid.org/0000-0003-1243-3834

2. Médico de la Universidad Católica de Santiago de Guayaquil; Investigador Independiente; Guayaquil, Ecuador; henry_llaguno@hotmail.com; iD https://orcid.org/0000-0002-2216-4255

3. Médica de la Universidad Católica de Santiago de Guayaquil; Investigador Independiente; Guayaquil, Ecuador; laurabarberant@gmail.com; iD https://orcid.org/0000-0002-3573-6005

4. Médica de la Universidad Católica de Santiago de Guayaquil; Investigador Independiente; Guayaquil, Ecuador; rominamendoza_g@hotmail.com; (D) https://orcid.org/0000-0002-1321-8151

CORRESPONDENCIA

Dennisse Isabel Parreño Grijalva

dennisse-parreno@gmail.com

Guayaquil, Ecuador

() RECIMUNDO; Editorial Saberes del Conocimiento, 2021 


\section{RESUMEN}

La atención pediátrica suele ser una de las más complejas en proporcionar por parte de lo médicos pues se asumen inconvenientes en la comunicación con el paciente de acuerdo a la edad. El dolor abdominal constituye uno de los motivos de consulta más frecuente en atención pediátrica. El abdomen agudo (AA) en la infancia es difícil de definir al ser un cuadro sindrómico de origen múltiple y de clínica muy variada. Durante enero de 2020 el brote de neumonía por SARS-CoV-2 en la ciudad de Wuhan, China, pareció obviar a los niños y a los adolescentes Se ha descubierto un nuevo síndrome hiperinflamatorio en niños y adolescente que a diferencia de los casos de Kawasaki clásico que en $80 \%$ de ellos ocurre en niños bajo 5 años de edad, estos niños hasta ahora reportados suelen ser de edad escolar o adolescentes. El propósito de la siguiente investigación es documentar los hallazgos científicos que evidencian alguna relación entre el abdomen agudo y enfermedad ocasionada por el SARS-CoV-2. La investigación se basa en una revisión y análisis documental acerca de los casos y estudios realizados en los pacientes pediátricos diagnosticados con COVID-19 en cuyos casos las manifestaciones clínicas han sido identificadas como dolor abdominal agudo para de cierta manera demostrar o desechar la relación existente entre el diagnostico de Abdomen agudo y las complicaciones a causa del contagio con el virus SARS-CoV-2. Para estas fechas se suman los estudios que se pueden desarrollar durante el tiempo que la enfermedad persista. Podemos concluir que en abdomen agudo en adolescentes con COVID-19 puede asociarse a la infección con el SARS-Cov-19 pero no hay evidencias concluyentes. Sin embargo, es importante señalar que un diagnóstico de Síndrome Inflamatorio Multisistémico puede tener etiologías clínicas comparables con el abdomen agudo pero estadísticamente puede ser más asociado al COVID-19 en adolescentes.

Palabras clave: COVID-19, SIM-C, SARS-Cov-19, Abdomen agudo, Dolor Abdominal, Adolescentes.

\section{ABSTRACT}

Pediatric care is usually one of the most complex to be provided by doctors, since inconveniences are assumed in communication with the patient according to age. Abdominal pain is one of the most frequent reasons for consultation in pediatric care. The acute abdomen (AA) in childhood is difficult to define as it is a syndromic picture of multiple origin and of very varied symptoms. During January 2020, the SARS-CoV-2 pneumonia outbreak in the city of Wuhan, China, seemed to ignore children and adolescents A new hyperinflammatory syndrome has been discovered in children and adolescents that unlike the cases of classic Kawasaki that in $80 \%$ of them occurs in children under 5 years of age, these children reported so far are usually of school age or adolescents. The purpose of the following investigation is to document the scientific findings that show some relationship between the acute abdomen and disease caused by SARS-CoV-2. The research is based on a review and documentary analysis about the cases and studies carried out in pediatric patients diagnosed with COVID-19 in whose cases the clinical manifestations have been identified as acute abdominal pain to in a certain way demonstrate or discard the relationship between the diagnosis of acute abdomen and complications due to infection with the SARS-CoV-2 virus. For these dates, the studies that can be developed during the time that the disease persists are added. We can conclude that acute abdomen in adolescents with COVID-19 can be associated with infection with SARSCov-19 but there is no conclusive evidence. However, it is important to note that a diagnosis of Multisystemic Inflammatory Syndrome may have clinical etiologies comparable to the acute abdomen but statistically it may be more associated with COVID-19 in adolescents.

Keywords: COVID-19, SIM-C, SARS-Cov-19, Acute abdomen, Abdominal pain, Adolescents.

\section{RESUMO}

Os cuidados pediátricos costumam ser um dos mais complexos para serem prestados pelos médicos, uma vez que pressupõem-se incómodos na comunicação com o paciente de acordo com a idade. A dor abdominal é um dos motivos mais frequentes de consulta em pediatria. $O$ abdome agudo $(A A)$ na infância é difícil de definir por se tratar de um quadro sindrômico de múltiplas origens e de sintomas muito variados. Durante janeiro de 2020, o surto de pneumonia SARS-CoV-2 na cidade de Wuhan, China, pareceu ignorar crianças e adolescentes. Uma nova síndrome hiperinflamatória foi descoberta em crianças e adolescentes que, ao contrário dos casos clássicos de Kawasaki, em 80\% deles ocorre em crianças menores de 5 anos de idade, essas crianças relatadas até agora são geralmente em idade escolar ou adolescentes. 0 objetivo da investigação a seguir é documentar as descobertas científicas que mostram alguma relação entre o abdome agudo e a doença causada pela SARS-CoV-2. A pesquisa se baseia em uma revisão e análise documental sobre os casos e estudos realizados em pacientes pediátricos com diagnóstico de COVID-19 em cujos casos as manifestações clínicas foram identificadas como dor abdominal aguda para de certa forma demonstrar ou descartar a relação entre os diagnóstico de abdome agudo e complicações devido à infecção pelo vírus SARS-CoV-2. A essas datas, somam-se os estudos que podem ser desenvolvidos durante o tempo de persistência da doença. Podemos concluir que o abdome agudo em adolescentes com COVID-19 pode estar associado à infecção por SARS-Cov-19, mas não há evidências conclusivas. No entanto, é importante observar que um diagnóstico de Síndrome Inflamatória Multissistêmica pode ter etiologias clínicas comparáveis ao abdome agudo, mas estatisticamente pode estar mais associado a COVID-19 em adolescentes.

Palavras-chave: COVID-19, SIM-C, SARS-Cov-19, abdômen agudo, dor abdominal, adolescentes. 


\section{Introducción}

La atención pediátrica suele ser una de las mas complejas en proporcionar por parte de lo médicos pues se asumen inconvenientes en la comunicación con el paciente de acuerdo a la edad.

En Pediatría de Atención Primaria, el dolor abdominal constituye uno de los motivos de consulta más frecuente, tanto en su presentación como episodios agudos, como en la presentación de dolores abdominales de manera intermitente y recurrente. En el caso de cuadros agudos, existe mayor número de causas orgánicas; mientras que, en el dolor abdominal crónico o recidivante, encontramos con mayor frecuencia una etiología funcional. (Lora, 2014)

Tabla 1. Etiología del dolor abdominal agudo infantil, en relación con la edad.

\begin{tabular}{|c|c|c|}
\hline & Frecuentes & Infrecuentes \\
\hline \multirow[t]{5}{*}{ Recien nacido 0.1 mes } & Sepsis & Enterocolitis necrotizante \\
\hline & Infección de orina & Ileo meconial \\
\hline & Colicos del lactante & Atresia yeyunal \\
\hline & Gastrcenteritis & Enfermedad de Hirschprung \\
\hline & Intolerancias alimentarias & Malformaciones intestinales \\
\hline \multirow[t]{6}{*}{ Lactante 1.12 meses } & Gastrcenteritis & Malformaciones intestinales \\
\hline & Traumatismos & Malformaciones urinarias \\
\hline & Colico del lactante & Invaginación intestinal \\
\hline & Intolerancia a alimentos & Fibrosis quistica \\
\hline & Infección urinaria & Torsión testicular/ovárica \\
\hline & & Hemia inguinal estrangulada \\
\hline \multirow[t]{5}{*}{ Preescolar $2-4$ años } & Gastroenteritis & Apendicitis aguda \\
\hline & Foco ORL & Tumores \\
\hline & Transgresiones alimentarias & Neumonia IObulo inferior \\
\hline & Infección urinaria & Colico nefritico \\
\hline & Sindrome hemolitico-urémico & \\
\hline \multirow[t]{7}{*}{ Escolar 4-11 aĥos } & Gastroenteritis aguda & Colecistitis aguda \\
\hline & Apendicitis aguda & Colelitiasis \\
\hline & FOCO ORL & Torsión testicular/ovárica \\
\hline & Púrpura Schönlein-Henoch & Impactación fecal \\
\hline & Traumatismo & Enfermedad inflamatoria intestinal \\
\hline & Infección urinaria & Cetoacidosis diabética \\
\hline & Neumonía & Cefalea/Migrana \\
\hline \multirow[t]{6}{*}{ Adolescente } & Apendicitis & Colecistitis \\
\hline & Enterocolitis & Pancreatitis \\
\hline & Ovulación/Menstruación & Úlcera péptica \\
\hline & Enfermedad inflamatoria intestinal & Diabetes \\
\hline & Enfermedad inflamatoria pelvica & Embarazo ectópico \\
\hline & & Funcional o psicosomático \\
\hline
\end{tabular}

Fuente: (Lora-Gómez, 2014)

Las estadísticas nos permiten identificar los caminos a seguir a la hora de desacartar ciertas enfermedades y concluir en un diagnóstico para su posterior tratamiento.

El abdomen agudo (AA) en la infancia es difícil de definir al ser un cuadro sindrómico de origen múltiple y de clínica muy variada. Con carácter general, podemos decir que el síntoma principal del AA es el dolor abdominal agudo (DAA). El DAA precisa un diagnóstico precoz para decidir el tratamiento más adecuado, sobre todo si éste debiera ser quirúrgico, en razón de los tres grupos etiopatogénicos de urgencias abdominales: obstructivas, inflamatorias o hemorrágicas. (Aparicio, 2005)

El tema con los DDA es que es menester del medico aliviar el dolor, tanto más si se

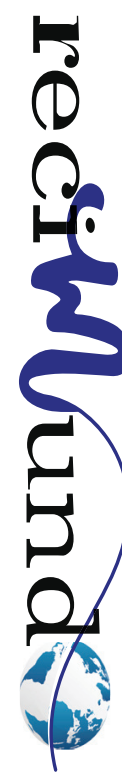


trata de un infante, es parte de la discusión medica suministrar analgesia en caso de Dolor Abdominal agudo o esperar un diagnóstico.

Durante enero de 2020 el brote de neumonía por SARS-CoV-2 en la ciudad de Wuhan, provincia de Hubei, China, pareció obviar a los niños y a los adolescentes. En la primera caracterización epidemiológica de COVID-19, publicada el 17 febrero de 2020 por los Centros de Control y Prevención de Enfermedades de China, se incluyeron 44.672 casos corroborados por RT- PCR hasta el 11 de febrero de 2020. Se reportaron 416 casos $(0,9 \%)$ entre las edades de 0 a 9 años, ninguna muerte y 549 casos (1,2\%) entre las edades de 10 a 19 años, incluyendo la muerte de un adolescente (tasa de letalidad del 0,002 \%). (Oliva, 2021)

Desde el inicio de la pandemia, la mayoría de reportes de vigilancia epidemiológica y publicaciones médicas han documentado que, a nivel mundial, aproximadamente 97-98\% de todos los casos de COVID registrados ocurren en adultos. Del restante porcentaje que ocurre en niños, la mayoría de ellos cursa con infección leve o asintomática. De aquellos que requieren hospitalización en salas de emergencia, salas de pediatría o unidades de cuidados intensivos pediátricos (UCIP), la mayoría se debe a dificultad respiratoria y neumonía. (Ulloa, Ivankovich, \& Yamazaki, 2020)

En el 2020 el Grupo de Estudio de Reumatología de la Sociedad Italiana de Pediatría emitió una alerta al gremio médico ante el incremento de casos de enfermedad de Kawasaki (EK) incompletos o atípicos, tendencia hacia el síndrome de activación macrofágica (SAM) e ingreso a UCIP. En varios de estos niños, se pudo documentar mediante laboratorio evidencia de infección reciente por SARS-CoV2 o se contaba con la historia de contacto con familiares positivos para el virus. Dos días después, la Sociedad de Cuidados Intensivos Pediátricos del Reino Unido y el Colegio Real de Pediatría y Salud del Niño del Reino Unido emitieron un comunicado de alerta mediante sus redes sociales y páginas web, debido al incremento también en niños de todas las edades en Londres y otras regiones del Reino Unido, de cuadros clínicos con traslape de hallazgos de Kawasaki atípico y síndrome de shock tóxico (SST), principalmente. Como hallazgos de interés en estos pacientes, aparte de su estado de shock 1hiperinflamatorio, éstos presentaban muchas manifestaciones gastrointestinales. (Ulloa, Ivankovich, \& Yamazaki, 2020)

La enfermedad de Kawasaki se caracteriza por una vasculitis aguda de etiología desconocida en la actualidad, que afecta principalmente las arterias coronarias y vasos cardiovasculares y cuyo riesgo de muerte está en los aneurismas gigantes que produce, afecta predominantemente a lactantes y niños. (Aquino \& Villanueva, 2020)

La pandemia nos ha sorprendido a todos, y este nuevo síndrome hiperinflamatorio en niños y adolescente es otra muestra más de ello. A diferencia de los casos de Kawasaki clásico que en $80 \%$ de ellos ocurre en niños bajo 5 años de edad, estos niños hasta ahora reportados suelen ser de edad escolar o adolescentes. (Ulloa, Ivankovich, \& Yamazaki, 2020)

El propósito de la siguiente investigación es documentar los hallazgos científicos que evidencian alguna relación entre el abdomen agudo y enfermedad ocasionada por el SARS-CoV-2.

\section{Metodología}

La investigación se basa en una revisión y análisis documental acerca de los casos y estudios realizados en los pacientes pediátricos diagnosticados con COVID-19 en 
cuyos casos las manifestaciones clínicas han sido identificadas como dolor abdominal agudo para de cierta manera demostrar o desechar la relación existente entre el diagnostico de Abdomen agudo y las complicaciones a causa del contagio con el virus SARS-CoV-2.

\section{Resultados}

El dolor abdominal agudo (DAA) comprende todas aquellas situaciones clínicas donde el síntoma principal es la sensación doIorosa intensa abdominal. Representa, por ello, un claro motivo de urgencia. El dolor puede ser secundario a múltiples causas, tanto relacionadas con patologías intraabdominales, como extraabdominales. (Lora-Gómez, 2014)

El tipo de dolor abdominal agudo puede ser, en función de su origen, abdominal o extraabdominal.

- Abdominal: el que se origina en cualquier segmento del tubo digestivo, en cualquier víscera sólida o estructura abdominal (hígado, bazo, páncreas, vesícula o mesenterio), del sistema genitourinario, de la columna vertebral, de la piel o estructuras blandas de la pared abdominal.

- Extraabdominal: cuyo origen puede situarse fuera del abdomen, como puede ser el tórax, estructuras ORL o bien neuropsicológico.

Fisiopatológicamente, el dolor abdominal agudo puede ser de tres tipos: dolor visceral, dolor somático o peritoneal y dolor referido.

El dolor visceral tiene su origen en los receptores situados en las vísceras huecas o sólidas abdominales, en las serosas que las recubren o en el peritoneo visceral. Es un dolor de transmisión lenta y se hace a través de las fibras $\mathrm{C}$ de las vías aferentes vegetativas. Se percibe con poca preci- sión, está mal localizado y es difuso. Frente a este dolor, el paciente tiende a doblarse sobre sí mismo para calmarlo, cambia frecuentemente de postura y muestra inquietud. La intensidad suele ser variable y se asocia con frecuencia a manifestaciones vagales. (Lora-Gómez, 2014)

El dolor somático o peritoneal tiene su origen en los receptores del peritoneo parietal, piel y músculos, y es conducido por las fibras aferentes de tipo $A$ de los nervios espinales, que son fibras de transmisión rápida. Se trata de un dolor que se localiza bien, punzante, muy intenso y que provoca una quietud absoluta, originando una clara posición antiálgica, la cual se intenta mantener de una forma permanente. (Lora-Gómez, 2014)

El dolor referido es el que tiene su origen en regiones alejadas de donde se manifiesta. Se trata de un dolor de proyección cerebral, cuyo origen puede ser tanto visceral como somático (Lora-Gómez, 2014) El llamado síndrome multisistémico inflamatorio de los niños (MIS-C) es una manifestación grave pero muy poco frecuente y cuyas manifestaciones clínicas recuerdan a las de la enfermedad de Kawasaki y al síndrome del choque séptico. Sus síntomas puede ser dolor abdominal incluyendo cuadros de abdomen agudo, fiebre y choque establecido. Aunque la mayoría de los niños sobreviven, se han publicado fallecimientos. Se ha postulado que podrían ser manifestaciones clínicas tardías de Covid-19, pero su asociación no se sabe si es causal o fortuita (Ruibal, Piñero, \& Rodríguez, 2020)

La primera publicación médica de casos pediátricos provino de Inglaterra el 6 de mayo 2020, designó el nombre de esta nueva entidad como síndrome pediátrico multisistémico inflamatorio (PMIS o PIMS por sus siglas en inglés) y propuso una definición de caso para su reconocimiento oportuno, se describen los primeros 8

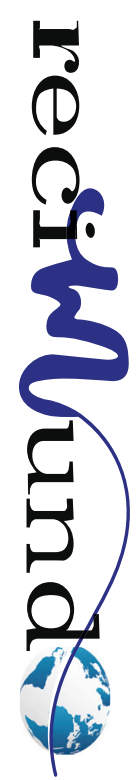


pacientes. En este reporte, los autores describen un aumento de casos de shock hiperinflamatorio, Kawasaki atípico, síndrome de shock por enfermedad de Kawasaki (SSEK) y SST con la presencia de tres criterios:

1. niños con fiebre persistente, inflamación y evidencia de disfunción de uno o más órganos (shock, o compromiso cardiaco, respiratorio, renal, gastrointestinal o neurológico) más otros hallazgos, incluidos criterios parciales o totales para EK;

2. exclusión de cualquier otra causa microbiana;

3. la prueba de reacción de polimerasa en cadena (RPC) para SARS-CoV-2 puede estar positiva o negativa.

A diferencia de la mayoría de niños con EK, todos ellos eran mayor de cinco años de edad, excepto un niño de 4 años. Estos pacientes tuvieron mucho síntoma gastrointestinal, todos progresaron a shock caliente vasopléjico refractario a volumen y requirieron de soporte inotrópico. El SARSCoV2 fue confirmado en dos pacientes y en otros cuatro hubo contacto con familiares positivos. (Ulloa, Ivankovich, \& Yamazaki, 2020) (Ruibal, Piñero, \& Rodríguez, 2020)

Después de esta definición, el Centro para el Control y Prevención de Enfermedades de Enfermedades (CDC) de E.U.A. emitió el 14 de mayo una definición modificada de caso y modificó el término a MIS-C. Al día siguiente, la OMS define el nuevo nombre como síndrome inflamatorio multisistémico (SIM/MIS) en niños y adolescentes con COVID-19. Dicha definición primaria de caso aplica para niños y adolescentes de 0 a 19 años de edad que cumplan con los criterios de fiebre > de 3 días, y 2 de los siguientes:

- Brote o conjuntivitis bilateral no supurativa o signos de inflamación mucocutánea (boca, manos o pies).
- Hipotensión arterial o shock.

- Hallazgos de disfunción miocárdica, pericárdica, valvular, o anormalidades coronarias (incluyendo hallazgos ecocardiográficos o aumento de troponina/ NT-proBNP.

- Evidencia de coagulopatía (por TP, TPT, elevación de Dímeros-D).

- Manifestaciones gastrointestinales agudas (diarrea, vómitos, o dolor abdominal).

- Elevación de marcadores de inflamación como velocidad de eritrosedimentación (VES), proteína C-reactiva (PCR), o procalcitonina.

- Ausencia de otra causa obvia de inflamación como sepsis bacteriana, o síndrome de shock tóxico estafilocóccico o estreptocóccico.

- Evidencia de COVID-19 (RT-PCR, test de antígeno o serología positiva), o contacto probable con pacientes con COVID-19. (Rodriguez \& Rivera, 2020)

El síndrome inflamatorio multisistémico (SIM-COVID-19) puede presentarse como complicación post infecciosa asociada a infección por SARS-CoV-2. 
Tabla 2. Denominaciones y características clínicas de SIM-COV-19.

\begin{tabular}{|c|c|c|c|}
\hline & $\mathrm{RCPH}$ & CDC & OMS \\
\hline Denominación & $\begin{array}{l}\text { Síndrome inflamatorio multisistémico pediá- } \\
\text { trico temporalmente asociado con COVID-19 }\end{array}$ & $\begin{array}{l}\text { Síndrome inflamatorio multisistémico en ni- } \\
\text { nos asociado a enfermedad COVID-19 }\end{array}$ & $\begin{array}{l}\text { Síndrome inflamatorio multisistémico en } \\
\text { niños y adolescentes con COVID-19 }\end{array}$ \\
\hline Fecha publicación & 1 de mayo de 2020 & 14 de mayo de 2020 & 15 de mayo de 2020 \\
\hline Edad & Niños & $<21$ años & $0-19$ años \\
\hline Fiebre & Persistente $>38,5^{\circ} \mathrm{C}$ & $\begin{array}{l}\text { Fiebre }>38^{\circ} \mathrm{C} \text { por } \geq 24 \mathrm{~h} \text { o fiebre subjetiva } \\
\geq \text { a } 24 \mathrm{~h}\end{array}$ & Fiebre $\geq 3$ días \\
\hline Hallazgos clínicos & $\begin{array}{l}\text { Disfunción de órganos única o múltiple } \\
\text { (shock, compromiso cardiaco, respiratorio, } \\
\text { renal, gastrointestinal, neurológico) }\end{array}$ & $\begin{array}{l}\text { Evidencia de inflamación de laboratorio }\left({ }^{*}\right) \text {, } \\
\text { enfermedad clínicamente grave que requiera } \\
\text { hospitalización con compromiso multisis- } \\
\text { témico }(\geq 2) \text { de órganos (cardiaco, renal, } \\
\text { respiratorio, hematológico, gastrointestinal, } \\
\text { dermatológico o neurológico) }\end{array}$ & $\begin{array}{l}\text { Y dos de las siguientes: } \\
\text { - Exantema o conjuntivitis bilateral no puru- } \\
\text { lenta o signos de inflamación muco-cutánea } \\
\text { - Hipotensión arterial o shock } \\
\text { - Compromiso cardiaco } \\
\text { - Evidencia de coagulopatía } \\
\text { - Compromiso gastrointestinal agudo } \\
\text { Y elevación de marcadores de inflamación } \\
\text { (PCR; PCT; VHS) }\end{array}$ \\
\hline Criterios de exclusión & $\begin{array}{l}\text { Sepsis bacteriana, shock tóxico estafilocócico } \\
\text { o estreptocócico, infecciones asociadas con } \\
\text { miocarditis como enterovirus }\end{array}$ & Diagnóstico alternativo plausible & $\begin{array}{l}\text { Sepsis bacteriana, shock tóxico estafilocócico } \\
\text { o estreptocócico }\end{array}$ \\
\hline $\begin{array}{l}\text { Evidencia de infección } \\
\text { por SARS-CoV-2 }\end{array}$ & RPC SARS-CoV-2 (+) o (-) & $\begin{array}{l}\text { Infección por SARS-CoV-2 diagnosticada } \\
\text { por RPC, serología o antígeno o exposición } \\
\text { a COVID-19 dentro de } 4 \text { semanas previo al } \\
\text { inicio de síntomas }\end{array}$ & $\begin{array}{l}\text { Evidencia de COVID-19 (RPC, antígeno o sero- } \\
\text { logía (+)) o contacto probable con pacientes } \\
\text { con COVID-19 }\end{array}$ \\
\hline
\end{tabular}

Fuente: (Izquiero, y otros, 2021)

En las series de casos reportadas se han descrito distintos fenotipos clínicos, los que se presentan habitualmente entre 2 y 6 semanas (mediana 4 semanas) posteriores a la infección aguda por SARS-CoV-2 y van desde un cuadro febril auto-limitado hasta presentaciones graves con compromiso hemodinámico y síntomas digestivos (dolor abdominal, vómitos, diarrea) que pueden o no tener componentes clínicos de la EK, hiper-coagulabilidad e inflamación. (Izquiero, y otros, 2021)

Considerando lo descrito en la literatura médica y para efectos prácticos, estas guías considerarán las siguientes cuatro presentaciones clínicas:

- SIM-COVID-19 sin EK, sin shock: síntomas inespecíficos en que predominan la fiebre, rash, compromiso gastrointestinal.

- SIM-COVID-19 con EK sin shock: cuadro febril asociado a elementos de EK
(2 o más criterios) sin compromiso hemodinámico.

- SIM-COVID-19 con shock/miocarditis: shock/miocarditis con o sin elementos de EK o compromiso gastrointestinal.

- SIM-COVID-19 con shock asociado a: tormenta de citoquinas /falla orgánica múltiple/ síndrome de activación de macrófagos (SAM) (ver diagnóstico diferencial). Este fenotipo es la forma menos frecuente de presentación, requiere de un alto índice de sospecha. (Izquiero, y otros, 2021)

Este nuevo síndrome (SIM-COVID-19), comparte características comunes con otras afecciones inflamatorias pediátricas incluyendo la EK, síndrome de shock tóxico estafilocócico y estreptocócico, sepsis y SAM, por lo que es fundamental un adecuado diagnóstico diferencial de otras etiologías. (Izquiero, y otros, 2021) 


\section{Enfermedad de Kawasaki}

SIM-COVID-19 puede presentar elementos clínicos compatibles con EK completo e incompleto. Los criterios diagnósticos de EK clásico son los siguientes:

Presencia de fiebre por 5 o más días y 4 o más de los siguientes:

- Eritema y fisura de labios, lengua aframbuesada, y/o eritema de mucosa oral o faríngea.

- Inyección conjuntival bulbar sin exudado.

- Rash: maculopapular, eritrodermia difusa, o eritema multiforme.

- Eritema y edema de manos y pies en la fase aguda, y/o descamación periungueal en fase subaguda.

- Linfadenopatía cervical (> 1,5 cm diámetro), usualmente unilateral.

Las principales diferencias descritas a la fecha entre EK y SIM-COVID-19 son que en el último cuadro presentan (Tabla 3). (Izquiero, y otros, 2021)

- Edad mayor que EK.

- Mayor compromiso digestivo y neurológico como forma de presentación inicial.

- Presencia de shock asociado a síntomas sugerentes de EK.

- Tendencia a la linfopenia, trombocitopenia y elevación mayor de parámetros inflamatorios: PCR, procalcitonina y dímero D.

Tabla 3. Diferencias clínicas y de laboratorio entre la Enfermedad de Kawasaki y SIM-

COV-19

\begin{tabular}{|lll|}
\hline & Enfermedad de Kawasaki & SIM-C \\
\hline Etnia & Origen asiática & Origen latino-afro caribeño \\
Etiología & Gatillado por agente infeccioso desconocido (iCoV?) & Asociación temporal con SARS-CoV-2 (4 a 6 semanas después) \\
Identificación de microorganismo & No & RPC SARS-CoV-2 $(+) \approx 25-30 \%$ \\
Edad & 6 meses -5 años (Mediana 3 años) & Serología SARS-CoV-2 IgG y/o IgM (+) $\approx 75 \%$ \\
Síntomas gastrointestinales & Raros & Mediana 9 años \\
Shock & $5 \%$ KSS (Kawasaki shock syndrome) & Frecuentes $\approx 100 \%$ \\
Alteraciones coronarias & $4-13 \%$ & Frecuente $\approx 60 \%$ \\
Parámetros inflamatorios & Elevados & $\approx 25 \%$ \\
Linfopenia & PCR - VHS & Extremadamente elevados \\
Necesidad de UPC & Raro & PCR - VHS \\
Resistencia a IGIV & $4 \%$ & Frecuente $\approx 80 \%$ \\
Letalidad & $10-20 \%$ & $\approx 80 \%$ \\
\hline $\begin{array}{l}\text { Adaptado de: Toubiana J, et al. BMJ } 2020 ; 369: m 2094 \text { doi: 10.1136/bmj.m2094. Jiang L et al. Lancet Infec Dis https://doi.org/10.1016/S1473-3099(20)30651-4. M. D. } \\
\text { Snape R M. Viner, Science 10.1126/science.abd6165 (2020). }\end{array}$ \\
\hline
\end{tabular}

Fuente: (Izquiero, y otros, 2021)

\section{Abdomen agudo}

Niños con SIM-C presentan fiebre asociada con dolor abdominal y vómito. Esto puede imitar la presentación de apendicitis aguda; las imágenes abdominales pueden ser necesarias para hacer una distinción. (Izquiero, y otros, 2021)

\section{Pancreatitis}

Es discutible si el SARS- CoV-2 es la causa de la pancreatitis o sólo una asociación temporal, en cuyo caso el diagnóstico sería pancreatitis idiopática y en forma concomitante una infección asintomática por SARSCoV-2. Sin embargo, se sabe que los virus pueden ser un agente causante de pancreatitis en aproximadamente $8-10 \%$ de los 
casos. Existe un reporte en la literatura que describe el aislamiento de SARS-CoV-2 por RPC en tejido pancreático, pero se desconoce si el mecanismo de daño del SARSCoV-2 pudiera ser citopático directo en páncreas o mediado por procesos inflamatorios y/o inmunológicos. Asimismo, no encontramos estudios que relacionaran carga viral de SARS-CoV-2 con la gravedad de la alteración pancreática. Faltan más estudios que aclaren la relación fisiopatológica entre SARS- CoV-2 y la injuria pancreática. (De la Barra, Izquierdo, Rivacoba, Román, \& Piñera, 2021)

Si bien es sabido que el síndrome inflamatorio multisistémico pediátrico asociado a COVID-19 (SIM-C) puede comprometer múltiples sistemas, entre ellos el hematológico, renal, hemodinámico, cardiovascular, y el gastrointestinal (incluido páncreas) hasta en un $92 \%$ de los pacientes. Se ha descrito que la temporalidad de la infección por SARS-CoV-2 y el desarrollo de pancreatitis aguda es heterogénea; algunos pacientes desarrollan síntomas de COVID-19 y dolor abdominal al inicio de la infección, sin embargo, se ha descrito otros casos en que la pancreatitis se desarrolla varios días después del diagnóstico de COVID-19. Se hace necesario que los médicos presten atención a la pancreatitis aguda y la consideren dentro de las posibles manifestaciones atípicas de COVID-19, tanto para aumentar la sospecha clínica, manejo oportuno, como para aumentar los reportes y mejorar así la casuística necesaria para develar esta posible asociación. (De la Barra, Izquierdo, Rivacoba, Román, \& Piñera, 2021)

Los pacientes con diagnóstico de SIM-COVID-19 deben ser hospitalizados y/o trasladados a un centro con disponibilidad de Unidad de Paciente Crítico Pediátrico, ya que 60 a $80 \%$ de ello requieren de soporte intensivo en su manejo. Las claves para el manejo exitoso y un mejor pronóstico son el reconocimiento precoz del shock, reposición y reanimación adecuada con fluidos, monitorización invasiva precoz, intubación y ventilación mecánica, optimización del aporte de oxígeno, minimizar el consumo de oxígeno y el uso apropiado de inotrópicos y vasopresores, según necesidad. (Izquiero, y otros, 2021)

\section{Conclusiones}

Un aspecto importante es el de analizar qué niños y adolescentes tienen mayores posibilidades de tener una enfermedad severa por Covid-19. Serían aquellos con factores de riesgo como tener menos de 1 año, o patologías crónicas subyacentes como enfermedades pulmonares incluidos casos de asma severo, pacientes con diabetes mellitus, enfermedades cardiopulmonares incluyendo la hipertensión arterial, cuadros de inmunosupresión, o enfermedades neuromusculares que causen discapacidad, u obesidades mórbidas. Otras comorbilidades que favorecerían la severidad de la infección por Covid-19 serían las enfermedades renales crónicas tributarias de diálisis y las enfermedades crónicas hepáticas. Sin embargo, los niños con terapias de inmunosupresión para tumores no parecen tener más riesgo de gravedad. Los pacientes neonatales infectados de sus madres no parecen tener tampoco especial gravedad. (Ruibal, Piñero, \& Rodríguez, 2020)

Hasta el momento existe poca información disponible respecto a la afectación pancreática asociada a infección por SARSCoV-2 en adultos y escasa en población pediátrica. Futuros estudios podrían ayudar a precisar la relación entre estos fenómenos, por lo que se hace relevante advertir a los profesionales de la salud sobre la posible relación y la necesidad de considerar la pancreatitis aguda como presentación atípica de COVID-19. (De la Barra, Izquierdo, Rivacoba, Román, \& Piñera, 2021)

Necesitamos con urgencia datos prospectivos y proveniente de redes multicéntricas, debido a la menor frecuencia de COVID-19

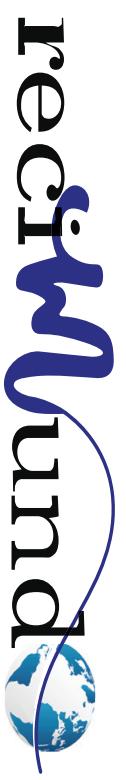


en pediatría. Para ello, Latinoamérica cuenta con diferentes redes de investigación y vigilancia que pueden ser de extrema utilidad. Mientras tanto, los médicos clínicos a cargo de estos niños y adolescentes, deben conocer los criterios diagnósticos del nuevo síndrome y estar alertas, sobre todo en países con número de casos crecientes en la actualidad como Brasil, Chile, y Ecuador, donde podría verse la mayor parte de pacientes graves semanas posteriores a la infección por SARS-CoV2. (Ulloa, Ivankovich, \& Yamazaki, 2020).

Respecto al Covid-19 resulta muy poco tiempo para identificar las complicaciones que puede causar, sobretodo por las mutaciones que han resultado del virus respecto a las características iniciales que mostró la enfermedad.

Para estas fechas no hay nada seguro, por el contrario se suman los estudios que se pueden desarrollar durante el tiempo que la enfermedad persista.

Podemos concluir que en abdomen agudo en adolescentes con COVID-19 puede asociarse a la infección con el SARS-Cov-19 pero no hay evidencias concluyentes. Sin embargo, es importante señalar que un diagnóstico de Síndrome Inflamatorio Multisistémico puede tener etiologías clínicas comparables con el abdomen agudo pero estadísticamente puede ser más asociado al COVID-19 en adolescentes.

\section{Bibliografía}

Aparicio, J. (2005). Abdomen agudo en el niño. Tratado de Urgencias en Pediatría. Protocolos diagnóstico-terapéuticos de Urgencias Pediátri-

\section{CITAR ESTE ARTICULO:}

Parreño Grijalva, D. I., Llaguno Mora, H. A., Barberán Torres, M. L., \& Mendoza Granda, R. I. (2021). Abdomen agudo en adolescentes con COVID-19. RECIMUNDO, 5(4), 121-131. https://doi.org/10.26820/recimundo/5.(4). oct.2021.121-131 cas SEUP-AEP, https://d1wqtxts1xzle7.cloudfront. net/48332387/ABDOMEN_AGUDO_-_ASOCIACION_ESPANOLA_DE_PEDIATRIA-with-cover-page-v2. pdf? Expires $=1633051502 \&$ Signature $=P 1 \mid \mathrm{U}-$ rrqdvT2LR JRHIGeDFXvel3I ZNvQ0pjn8FPxCX2FRDWT60Wgl -uWvRx0QLy9wZQYLUdrJHGT6w6nLG-Xz3CA90J4kG0ErFo60KHuX.

Aquino, C., \& Villanueva, L. (2020). Síndrome de Kawasaki en población pediátrica durante la pandemia por la COVID-19: realidad o mito. Revista cubana de Pediatría, http://revpediatria.sld.cu/index.php/ped/article/view/1169/705.

De la Barra, S., Izquierdo, G., Rivacoba, M., Román, G., \& Piñera, C. (2021). Pancreatitis aguda asociada a infección por SARS-CoV-2 en un paciente pediátrico. Andes pediatrica, http://dx.doi. org/10.32641/andespediatr.v92i6.3360 .

Izquiero, G., Cofré, F., Delpiano, L., Conca, N., Verdugo, P., Aceveso, V., \& Tapia, L. (2021). Recomendaciones para la sospecha diagnóstica y manejo del Síndrome Inflamatorio Multisistémico (SIM-COVID-19) en contexto pandemia SARSCoV-2. Revista chilena de infectología, http://dx. doi.org/10.4067/S0716-10182021000300370.

Lora, R. (2014). Dolor abdominal agudo en la infancia. PEDIATRÍA INTEGRAL, 219-228.

Oliva, J. (2021). COVID-19 en la niñez y adolescencia. Alerta, 4(1), 48-60.

Rodriguez, R., \& Rivera, M. (2020). Síndrome inflamatorio multisistémico asociado a COVID-19 en niños y adolescentes. Revista Latinoamericana de infectología Pediátrica, 33(3), 115-118.

Ruibal, J., Piñero, M., \& Rodríguez, M. (2020). LA ENFERMEDAD COVID-19 EN LA INFANCIA Y ADOLESCENCIA. ANALES RANM, 179-189.

Ulloa, R., Ivankovich, G., \& Yamazaki, M. (2020). Síndrome inflamatorio multisistémico asociado a COVID-19 en niños y adolescentes: un llamado al diagnóstico. Revista chilena de infectología, http:// dx.doi.org/10.4067/s0716-10182020000300199

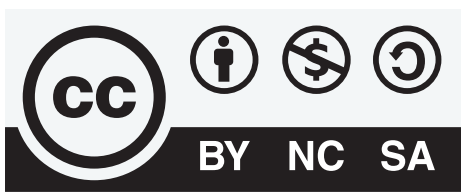

CREATIVE COMMONS RECONOCIMIENTO-NOCOMERCIAL-COMPARTIRIGUAL 4.0 . 


\section{Síndrome Inflamatorio Multisistémico asociado a COVID-19 (SIM-C)}
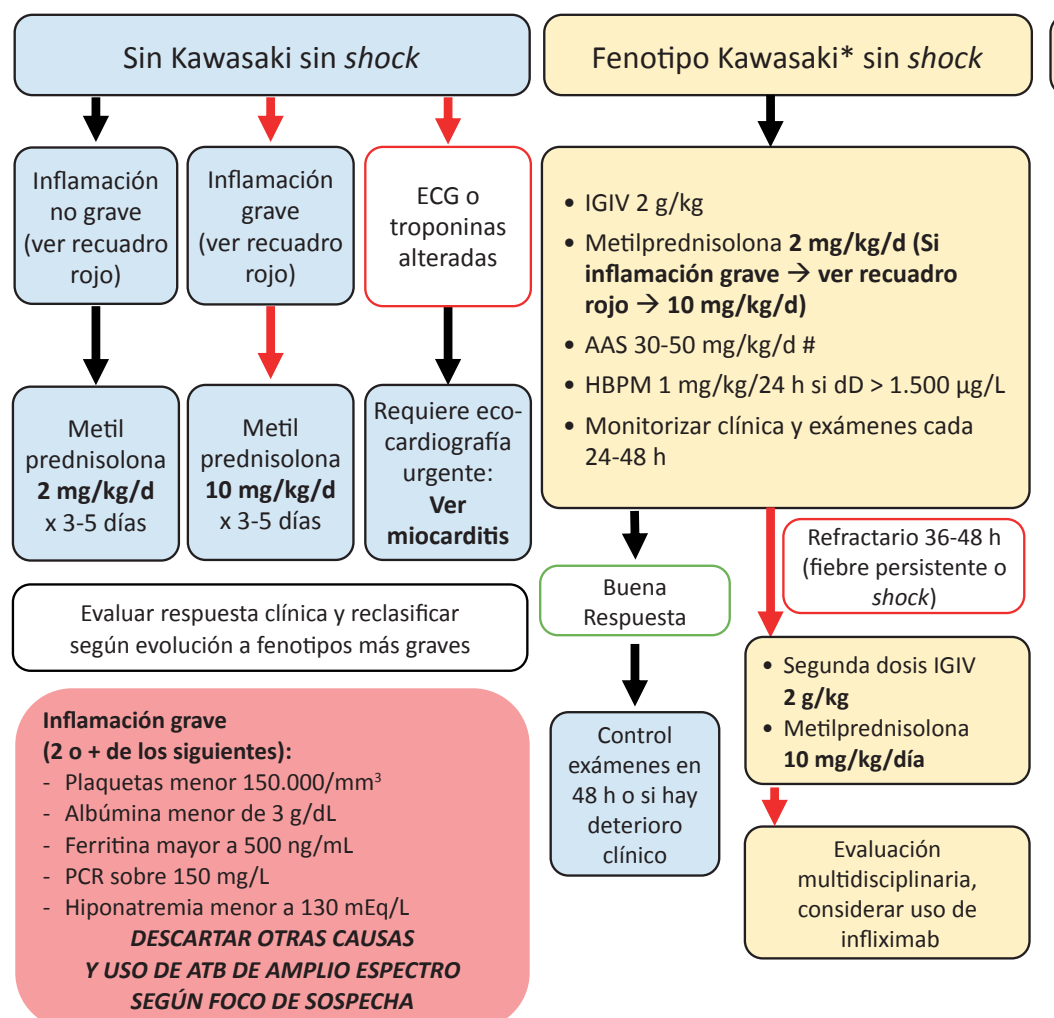

- IGIV $2 \mathrm{~g} / \mathrm{kg}$

- Metilprednisolona $2 \mathrm{mg} / \mathrm{kg} / \mathrm{d}$ (Si inflamación grave $\rightarrow$ ver recuadro rojo $\rightarrow 10 \mathrm{mg} / \mathrm{kg} / \mathrm{d}$ )

- AAS $30-50 \mathrm{mg} / \mathrm{kg} / \mathrm{d} \#$

- HBPM $1 \mathrm{mg} / \mathrm{kg} / 24 \mathrm{~h}$ si dD > $1.500 \mu \mathrm{g} / \mathrm{L}$

- Monitorizar clínica y exámenes cada 24-48 h

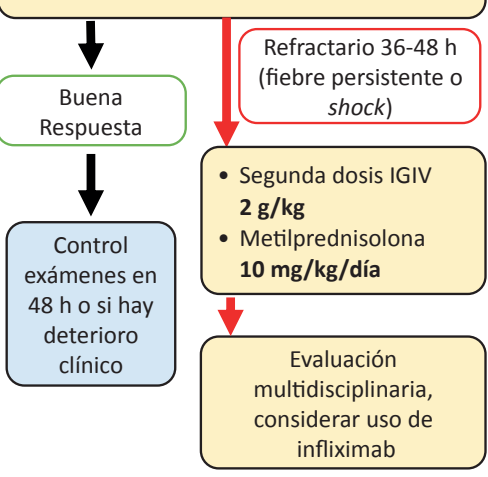

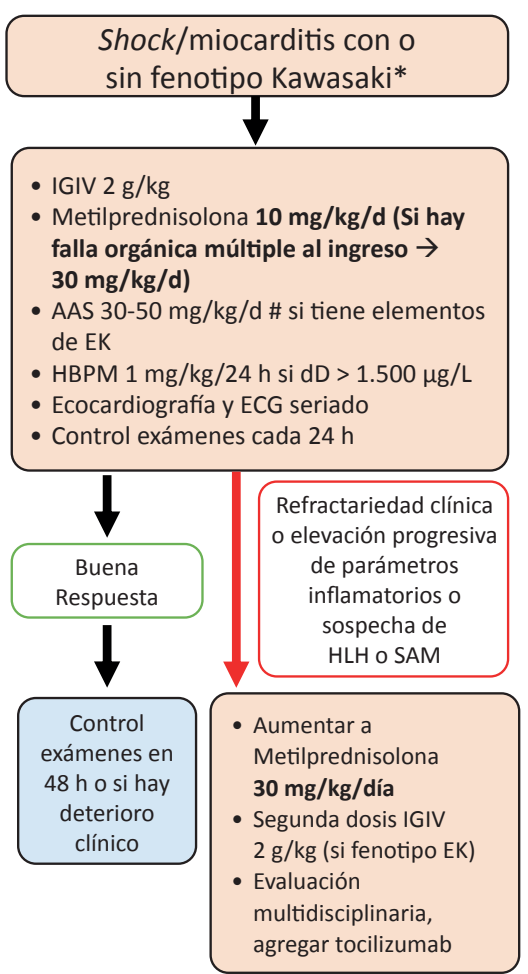

Shock/miocarditis con o sin fenotipo Kawasaki*

- IGIV $2 \mathrm{~g} / \mathrm{kg}$ falla orgánica múltiple al ingreso $\rightarrow$ mg/kg/d)

AAS $30-50 \mathrm{mg} / \mathrm{kg} / \mathrm{d}$ \# si tiene elementos

*Fenotipo Kawasaki: 2 o más criterios clínicos de EK además de la fiebre.

Abreviaciones: EK: Enfermedad de Kawasaki; VHS: velocidad de sedimentación; PCR: proteína C reactiva; ELP: electrolitos plasmáticos; TP: tiempo protrombina; TTPA: tiempo de tromboplastina activada; ECG: electrocardiograma; IGIV: inmunoglobulina intravenosa; AAS: ácido acetilsalicílico; HBPM: heparina de bajo peso molecular; HLH: linfohistiocitosis hemofagocítica; SAM: síndrome de activación macrofágica.

\section{SEGUIMIENTO Y CONSIDERACIONES:}

- Continuación y posterior suspensión de corticoides:

- Si se usaron dosis Metilprednisolona $2 \mathrm{mg} / \mathrm{kg} /$ día: pasar a Prednisona $1 \mathrm{mg} / \mathrm{kg} / \mathrm{d}$ por 3-5 días, luego 0,5 mg/kg/día por 3-5 días y suspender

- Si se usaron dosis altas de Metilprednisolona (mayor $10 \mathrm{mg} / \mathrm{kg} / \mathrm{d}$ ): pasar a Prednisona $2 \mathrm{mg} / \mathrm{kg} / \mathrm{d} 2 \mathrm{mg} / \mathrm{kg}$ por 5 días; $1 \mathrm{mg} / \mathrm{kg} / \mathrm{día} \mathrm{por} 5 \mathrm{días}$ y luego $0,5 \mathrm{mg} / \mathrm{kg} /$ día por 5 días. En estos pacientes existe un mayor riesgo de rebote de la enfermedad y de insuficiencia suprarrenal por lo que requiere una suspensión lenta y progresiva con traslape a hidrocortisona (ver documento) y medición de cortisol basal previo a la suspensión.

- \# Ácido acetilsalicílico (AAS):

En Fenotipo Kawasaki mantener dosis altas hasta $48-72 \mathrm{~h}$ afebril, luego dosis antiagregante plaquetaria 3-5 mg/kg/d por 6 semanas. Si hay dilataciones en ecocardiograma debe mantenerse hasta que éstas regresen.

No usar AAS en pacientes con plaquetas menor a 80.000 o riesgo de sangrado

- Heparina de bajo peso molecular (HBPM):

Mantener HBPM $1 \mathrm{mg} / \mathrm{kg} / 24 \mathrm{~h}$ * si DD mayor a $1.500 \mu \mathrm{g} / \mathrm{L}$ (*podría indicarse 0,5 mg/kg/cada $12 \mathrm{~h}$, pero dado igual resultado, se recomienda dosis diaria para evitar dolor y punción innecesaria).

Suspender ante DD en descenso con valores menor a $1.500 \mu \mathrm{g} / \mathrm{L}$, o al alta asegurando disminución de los parámetros inflamatorios

Considerar dosis de tratamiento anticoagulante $1 \mathrm{mg} / \mathrm{kg}$ cada $12 \mathrm{~h}$ si hay evidencia de trombosis.

Figura 1. Flujograma para el manejo farmacológico de pacientes con SIM-COV-19 según fenotipos clínicos

Fuente: (Izquiero, y otros, 2021) 